\title{
Whole transcriptome analysis of the hippocampus: toward a molecular portrait of epileptogenesis
}

\author{
Oswaldo K Okamoto ${ }^{1 *}$, Luciana Janjoppi ${ }^{1}$, Felipe M Bonone ${ }^{1}$, Aline P Pansani ${ }^{1}$, Alexandre V da Silva², \\ Fúlvio A Scorza', Esper A Cavalheiro'
}

\begin{abstract}
Background: Uncovering the molecular mechanisms involved in epileptogenesis is critical to better understand the physiopathology of epilepsies and to help develop new therapeutic strategies for this prevalent and severe neurological condition that affects millions of people worldwide.

Results: Changes in the transcriptome of hippocampal cells from rats subjected to the pilocarpine model of epilepsy were evaluated by microarrays covering 34,000 transcripts representing all annotated rat genes to date. Using such genome-wide approach, differential expression of nearly 1,400 genes was detected during the course of epileptogenesis, from the early events post status epilepticus (SE) to the onset of recurrent spontaneous seizures. Most of these genes are novel and displayed an up-regulation after SE. Noteworthy, a group of 128 genes was found consistently hyper-expressed throughout epileptogenesis, indicating stable modulation of the p38MAPK, JakSTAT, PI3K, and mTOR signaling pathways. In particular, up-regulation of genes from the TGF-beta and IGF-1 signaling pathways, with opposite effects on neurogenesis, correlate with the physiopathological changes reported in humans.

Conclusions: A consistent regulation of genes functioning in intracellular signal transduction regulating neurogenesis have been identified during epileptogenesis, some of which with parallel expression patterns reported in patients with epilepsy, strengthening the link between these processes and development of epilepsy. These findings reveal dynamic molecular changes occurring in the hippocampus that may serve as a starting point for designing alternative therapeutic strategies to prevent the development of epilepsy after acquired brain insults.
\end{abstract}

\section{Background}

Chronic brain disorders have a profound impact on life quality since most of them are associated with cognitive impairment, and disturbance of personality or behavior. With the tendency of global population aging, the incidence of people living with such disabilities will dramatically increase in the next decades. Epilepsy is one example of prevalent and severe neurological condition, affecting approximately 50 million people worldwide [1].

Epidemiological studies reveal that about 20 to $30 \%$ of patients with epilepsy are refractory to the currently available therapies and continue to have seizures

\footnotetext{
* Correspondence: keith.nexp@epm.br

'Disciplina de Neurologia Experimental, Departamento de Neurologia e
} Neurocirurgia, Universidade Federal de São Paulo throughout their lives [2]. Temporal lobe epilepsy (TLE), which is characterized by atrophy of mesial temporal structures and hippocampal sclerosis, is the most frequent form of partial epilepsy and also the most common form of drug-refractory epilepsy [3].

The mechanisms of action of most clinically used drugs in human established epilepsies are based upon the synchronized neuronal activity and unbalance between inhibitory and excitatory neurotransmission, which are common features linked to the pathogenesis of epilepsy [4]. In that sense, voltage-gated ion channels, gabaergic, and glutamatergic systems are the classic therapeutic targets. However, these drugs act to restrain epileptic seizures in already established epilepsies rather than preventing the development of epilepsy after acquired brain insults.
C Biomed Central

(c) 2010 Okamoto et al; licensee BioMed Central Ltd. This is an Open Access article distributed under the terms of the Creative Commons Attribution License (http://creativecommons.org/licenses/by/2.0), which permits unrestricted use, distribution, and reproduction in any medium, provided the original work is properly cited. 
Uncovering the molecular mechanisms involved in epileptogenesis is critical to understand the physiopathology of epilepsies and to help develop new therapeutic strategies based on drugs with anti-epileptogenic activity. The identification of potential therapeutic targets, however, should be facilitated by the knowledge of genes, proteins, and signaling pathways altered during the different stages of epilepsy development.

In the post-genomic era, DNA microarrays are being widely used as an experimental tool to monitor changes in gene expression levels in different pathologies. In epilepsy, the clinical implications of the microarray technology are illustrated in a few recent publications in the literature [5-9]. One drawback of such approach in humans, however, is that the experimental design is not trivial due to the lack of appropriate control samples of healthy brain tissue. Furthermore, surgical specimens often available for study do not allow correlation with the early stages of the disease. Alternatively, key molecular alterations during epileptogenesis can be examined in animals subjected to classical models of experimental epilepsy. Several well-characterized models have been described in the last decades and in many ways they mimic complex partial seizures observed in patients with TLE [10].

Recent reports of gene expression profiling are available for some of these animal models [11-15], albeit with partial transcriptome coverage and time points more closely related with responses to either status epilepticus $(S E)$ or cumulative chronic spontaneous seizures. A comprehensive gene expression profiling designed for the study of epileptogenic process, from the early molecular changes induced by hippocampal injury to the onset of epilepsy, is still lacking.

In this work, we performed a genome wide analysis of genes differentially expressed during epileptogenesis. Virtually, all possible changes in the rat transcriptome were monitored at distinct time points corresponding to the latent to chronic phase transition of the pilocarpine model of epilepsy, one the most extensively studied chemically induced model of TLE [16-18]. Genes identified as being differentially expressed were classified based on their respective biological functions to envisage processes and pathways likely implicated in epileptogenesis. Genes stably up-regulated and working in a concerted fashion were identified, some of which displaying a parallel expression pattern in humans with epilepsy, suggesting their possible value as targets for therapy.

\section{Methods}

\section{Animal model}

Male adult Wistar rats (200-250 g) were used throughout the study. Animals were housed under standard controlled conditions (7:00 AM/7:00 P.M. light/dark cycle; $20-22^{\circ} \mathrm{C}$; $45-55 \%$ humidity) with food and water ad libitum. All efforts were made to minimize animal suffering following the proposal of International Ethical Guideline for Biomedical Research (CIOMS/OMS, 1985). The study was approved by the Ethics Committee for animal research of the Federal University of São Paulo, Brazil (CEP 2053/07).

Animals ( $n=5$ per experimental group) were subjected to the pilocarpine model of epilepsy $[19,20]$. Briefly, rats were pre-treated with a subcutaneous injection of scopolamine methylnitrate $(1 \mathrm{mg} / \mathrm{kg}$, to minimize peripheral cholinergic effects), followed by a single dose of pilocarpine $(350 \mathrm{mg} / \mathrm{kg}$, dissolved in saline) (Sigma Chemical, USA) injected intraperitoneally. Control animals received the same amount of saline only. After $4 \mathrm{~h}$ of $S E$, pilocarpine-treated rats (Pilo) received diazepam (8 mg/kg i.p.) to block behavioral and electrographic seizures. Occurrence of spontaneous seizures was detected by continued video monitoring of animals.

\section{Microarray hybridization}

Gene expression profiling was analyzed in hippocampi of rats treated with pilocarpine at different times during the course of epileptogenesis: 3 days post-SE (3 D), 7 days post-SE (7 D), and immediately (up to $12 \mathrm{~h}$ ) after the first spontaneous seizure (Chronic). All three pilocarpine subgroups had a corresponding age-matched control group (saline-treated rats), from which normal hippocampi samples were obtained at the same experimental time points. Rats were killed by decapitation and the hippocampi were removed at $4{ }^{\circ} \mathrm{C}$ within a period no longer than three minutes. Brain tissues were snap frozen in liquid nitrogen and stored at $-80^{\circ} \mathrm{C}$ until RNA extraction with the RNeasy kit (Qiagen), following the manufacturer's protocol. Evaluation of RNA quantification and purification was carried out by measuring absorbance at 260 and $280 \mathrm{~nm}$. A260/A280 ratios in the range of 1.8-2.0 were considered satisfactory for purity standards. Denaturing agarose gel electrophoresis was used to assess the quality of RNA samples.

Independent microarray hybridizations were carried out for each sample ( $\mathrm{n}=5$, per experimental group) with oligonucleotide microarrays covering 34,000 transcripts representing all known and predictive genes of the rat genome (CodeLink $^{\text {Ts }}$ Rat Whole Genome Bioarrays, GE Healthcare), following the manufacturer's protocol. Detailed descriptions of the Bioarray platform and expression data are publicly available, according to MIAME guidelines, at the GEO database under the accession numbers GPL2896 and GSE14763. Briefly, total RNA was extracted with RNeasy spin columns and treated with RNAse free-DNAse (Qiagen). One microgram of total RNA was reverse transcribed in the presence of T7- oligo dT primer. The resulting cDNA was 
used for in vitro transcription reaction using T7 RNA polymerase and biotinylated dUTP. Ten micrograms of target cRNA was fragmented at $94^{\circ} \mathrm{C}$ for $20 \mathrm{~min}$ and hybridized to the bioarrays at $37^{\circ} \mathrm{C}$ for $18 \mathrm{~h}$, under 300 rpm agitation. After staining with streptavidin-conjugated Cyanine- 5 dye, the slides were washed and fluorescence was measured using an Axon GenePix 4000B Scanner (Axon Instruments Inc).

\section{Gene Expression measurement}

The fluorescent images were captured using GenePix Pro v.4.1 (Axon Instruments Inc) and the light intensities were quantified, corrected for background noise, and normalized with the CodeLink ${ }^{\text {Tim }}$ Expression Analysis v4.1. Spots with background contamination, shape irregularity, or pixel saturation were filtered out. Only spots flagged as "good" (G) or "low" (L) were considered in the subsequent analysis. Since the CodeLink ${ }^{\text {tim }}$ system is a one-color platform, we grouped the meaningful comparisons in pairs to form ratios, as usual in two-color co-hybridized microarray platforms. Differentially expressed genes were identified by comparing the fluorescence values of a given spot (transcript) in samples from pilocarpine-treated rats vs. pair-matched control rats, using an intensity-dependent dynamic cutoff with 99\% credibility level. Genes displaying expression changes equal or higher than two fold $(\mathrm{P} \leq 0.05)$ were included in the analysis. These differentially expressed genes were grouped by unsupervised hierarchical clustering using correlation and average linkage metrics as described elsewhere [21].

\section{Gene Enrichment and Functional Annotation Analysis}

Given the lists of differentially expressed genes, we performed an ontology term enrichment analysis using the DAVID 2.1 tool to find gene functional classes specifically associated with those lists [22]. In such analysis, the statistical association between being differentially expressed and belonging to a given category is accessed by the Fisher Exact test. The ontologies used were those defined by the KEGG database of metabolic pathways [23] and by the Gene Ontology Consortium [24]. The probe-to-GO and the probe-to-KEGG mapping were established based on the official annotation provided by the manufacturer.

\section{Real-time PCR quantification}

Gene expression was quantified in hippocampi of rats treated either with saline or pilocarpine, at different times during the course of epileptogenesis $(n=5$ per experimental group). One microgram of total RNA was used to synthesize cDNA by extension with oligo-dT primers and 200 U of Superscript II Reverse Transcriptase (Invitrogen Life Technologies). Quantitative reverse-transcription polymerase chain reaction was performed in a ABI 7500 Real-Time PCR System platform (Applied Biosystems) by the Sybr-Green approach (Platinum SYBR Green qPCR SuperMix-UDG, Invitrogen Life Technologies), using ROX as passive reference dye. All samples were analyzed in the same plate, in a single PCR run, and under identical conditions. Amplification specificity was assessed by dissociation curve analysis. Normalization of quantitative data was based on the expression of the housekeeping gene glyceraldehyde-3phosphate dehydrogenase (GAPDH). Quantification was based on $2^{-\triangle \Delta C T}$ method, using corresponding agematched control samples as calibrators. Amplification reactions contained $2 \mu \mathrm{L}$ of $1: 10$ diluted $\mathrm{cDNA}$ and 10 pmoles of each primer. Basic amplification cycle suggested by the manufacturer was used, with an annealing temperature of $60^{\circ} \mathrm{C}$. Primer sequences were obtained elsewhere: NESTIN FOR 5' AGCAACTGGCACACCT CAAG 3', NESTIN REV 5' GGTGTCTGCAAGC GAAAGTTC 3', GFAP FOR 5' CTCAGTACGAGG CAGTGGCC 3', GFAP REV 5' CGGGAAGCAACGT CTGTGA 3' [25], IGF1 FOR 5' CACAGGCTATG GCTCCAGCAT 3', IGF1 REV 5' TCTCCAGCCTCCT CAGATCACA 3' [26], CDK1 FOR 5' CGGTTGACATCTGGAGCATA 3', CDK1 REV 5' GCATTTTC GAGAGCAAGTCC 3', p18(INK4c) FOR 5' ACCG AACTGGTTTTGCTGTC 3', p18(INK4c) REV 5' GGGCAGGTTCCCTTCATTAT 3' [27], TGFbeta1 FOR 5' GAGAGCCCTGGATACCAACTACTG 3', TGFbeta1 REV 5' GTGTGTCCAGGCTCCAAATGTAG 3' [28], GAPDH FOR 5' GAACCTGCCGTGGGTAGAG 3', GAPDH REV 5’ AGGTCGGTGTGAACGGATTTG 3' [29].

\section{Statistical Analyses}

Microarray data: statistically significant differences among treatments were determined by the Student's $t$ test and the Fisher Exact test. All conclusions are based on at least $5 \%$ level of significance $(P \leq 0.05)$. Real-time PCR data: analysis was performed with the GraphPad Prism software, v.3.00 for Windows (San Diego, CA, USA). Data were analyzed by Two-way ANOVA, Treatment (2) $\times$ Time (3), with Bonferroni as post-hoc test, since there was a normal distribution. Significance was established at the $\mathrm{P} \leq 0.05$ level.

\section{Results}

Latent period of the pilocarpine model is marked by dynamic changes at the molecular level

As extensively described by Turski et al., 1983 [19], a single high dose of pilocarpine, a potent muscarinic cholinergic agonist originally isolated from the leaves of South American shrubs, induced sequential behavioral changes characteristic of sustained epileptic activity. Few minutes after pilocarpine administration, the animals 
exhibited stereotypical oral and mastigatory movements, hypokinesia, salivation, chewing, sniffing-head, tremor, and partial or generalized limbic seizures that evolved to $S E$. The mortality within the first $24 \mathrm{~h}$ of pilocarpine administration was around $30 \%$. Only those animals that achieved $S E$ and survived were included in the study ( $n=5$ per experimental group). This acute phase was followed by a latent period during which the animals were initially comatose or unresponsive to their environment due to $S E$ and progressively returned to normal behavior, usually within three days post-SE. This period is also described as a "silent" period due to the absence o behavioral and electrographic evidences of seizures. Spontaneous and recurrent seizures typically characterized by facial automatism, forelimb clonus, and rearing followed by loss of postural control and generalized clonic seizures lasting 25-35 sec. tend to occur later on, being a hallmark of the chronic period of the pilocarpine model. Time to first spontaneous seizure ranged from nine to 17 days. The latent period of the pilocarpine model of epilepsy is known to vary among animals and our results are in agreement with the literature [16].

Although clinically silent, the period spanning $S E$ and the beginning of spontaneous seizure activity is critical to evaluate changes that might be relevant to epileptogenesis. Therefore, a whole transcriptome analysis was performed with the purpose of identifying genes differentially expressed after pilocarpine-induced $S E$. The starting total RNA used in the hybridizations was extracted from hippocampi at different times during the course of epileptogenesis. After a typical microarraybased analysis (Figure 1), alterations in the expression of almost 1,400 genes were detected, suggesting an intense molecular activity during the latent to chronic phase transition of the pilocarpine model. A total of 736, 328, and 326 genes were found differentially expressed three days post-SE (D3), seven days post-SE (D7), and after the first spontaneous seizure (Chronic), respectively. Noteworthy, the vast majority of these differentially expressed genes (90\%) had their expression up-regulated after $S E$, while the remainder $10 \%$ corresponded to hypo-expressed genes at the same time points analyzed $(\mathrm{D} 3=81, \mathrm{D} 7=19$, Chronic $=31)$.

\section{Pilocarpine-induced SE promotes constitutive changes in gene expression}

Among the 1,400 differentially expressed genes, of particular interest was the finding of a large group of 128 genes commonly over-expressed in D3, D7, and Chronic groups, indicative of a stable gene up-regulation throughout the latent to chronic phase transition of the pilocarpine model. As depicted in the Venn diagram of figure $1 \mathrm{~B}$, this amount of commonly over-expressed genes is higher than the number of genes exclusively up-regulated at each of the respective time points, with the exception of D3. In contrast, among the down-regulated genes, only two genes were found simultaneously hypo-expressed at all time points analyzed and, to date, no biological functions have been described for them.

\section{Biological processes and signaling pathways associated with epileptogenesis}

When functionally classifying genes based on the Gene Ontology Consortium terminology, a myriad of biological processes could be related to the genes affected by $S E$. Since the overall representation of genes and corresponding annotated functions in the entire rat genome may confer a bias in this type of functional classification and because a single gene may belong to multiple functional categories, one major challenge is to distinguish processes and functions specifically associated with epileptogenesis from those found due to random chance. Therefore, a statistical test was applied to circumvent this issue and identify functional categories over-represented among the genes regulated by $S E$ in hippocampal cells.

Figure 2 summarizes the number of enriched genes, their corresponding molecular functions, and respective $P$-values for functional association. Such classification strategy revealed that the subset of 128 genes commonly up-regulated in D3, D7, and chronic groups were particularly enriched in genes functioning in immune response (including humoral defense mechanism and, more specifically, complement and coagulation cascades), cell motility, apoptosis, and intracellular signaling cascades. The differentially expressed genes and respective functional categories are depicted in table 1. Regarding signaling pathways, those corresponding to over- and hypoexpressed genes during all experimental times studied after $S E$ are illustrated in table 2. From this later analysis, it can be noticed that MAPK, Jak-STAT, Phosphatidyl inositol, TGF-beta, and mTOR signaling pathways were found regulated in pilocarpine-treated animals throughout the epileptogenesis period evaluated.

Differential expression of the selected genes Nestin, $C D K 1, p 18(I N K 4 c), T G F-\beta 1, I G F-1$ and GFAP was quantified by real-time PCR in order to confirm the microarray results. Similar results were found with both techniques. Compared with the respective control groups, Nestin, CDK1, and $p 18(I N K 4 c)$ genes were found significantly over-expressed only three days after SE. On the other hand, TGF- $\beta 1, I G F-1$, and GFAP genes displayed significant variations in expression at all times analyzed after SE (Figure 3).

\section{Discussion}

High throughput gene expression profiling data can be correlated with a certain pathological condition, subtype or phase of diseases. This genomic approach could 


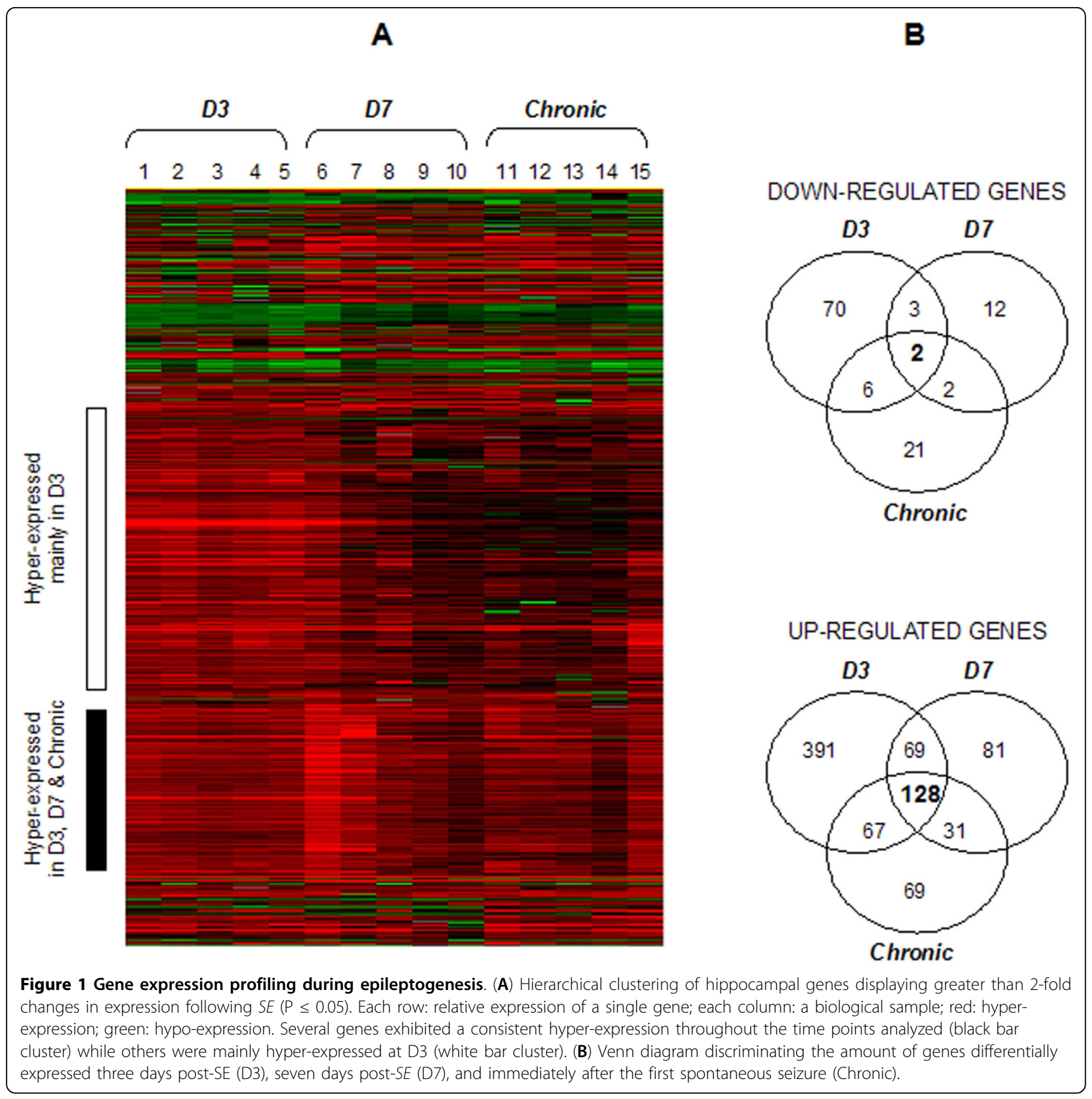

facilitate the identification of molecular pathways and physiological processes involved in the development of complex multifactorial diseases such as epilepsy.

In animal models, differentially expressed genes have been reported in response to $S E$ induced by kainic acid [11], pilocarpine [12,13], and by electric stimulation (Kindling) [14,15]. Despite the large amount of data already accumulated, a comparative meta-analysis is difficult to carry out due to the different experimental design and microarray platforms used in studies of such kind. The amount of genes/transcripts interrogated in most studies ranged from 1560 to 8000 , corresponding to up to $25 \%$ of genes identified in the rat genome. Furthermore, the interval after $S E$ in which gene expression has been evaluated varies from as early as one day, when many genes functioning in stress defense, inflammation, and cell death are regulated in response to the excitotoxic insult, to as late as 100 days post- $S E$, when gene expression reflects a neural tissue suffering from multiple events of spontaneous seizures, with frequency and intensity of seizures varying among testing animals. 


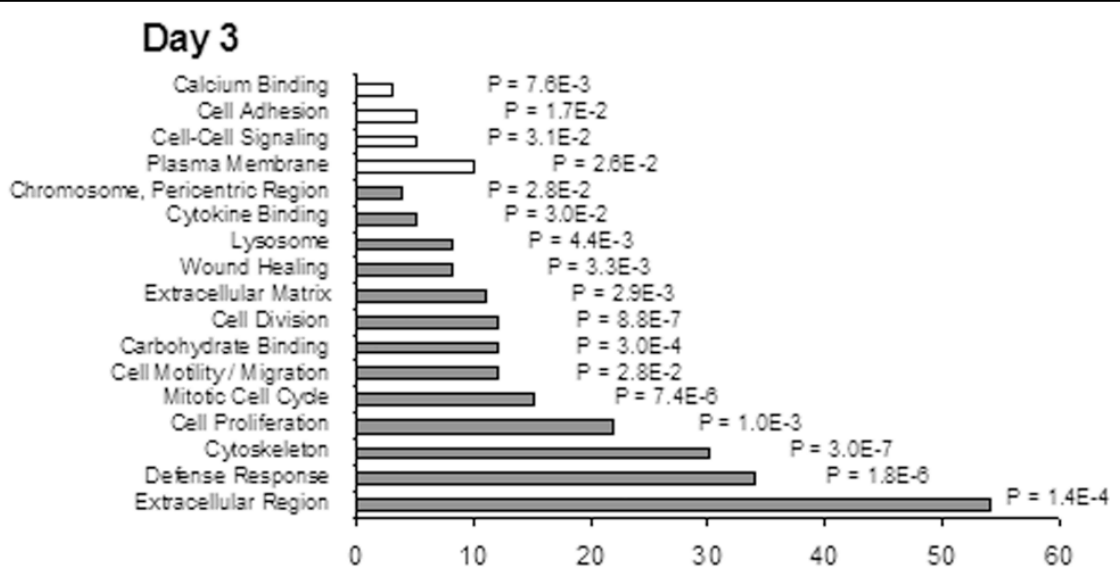

Day 7

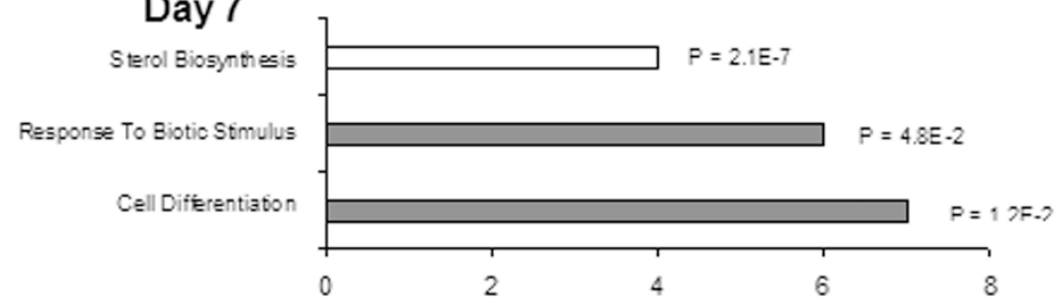

Chronic

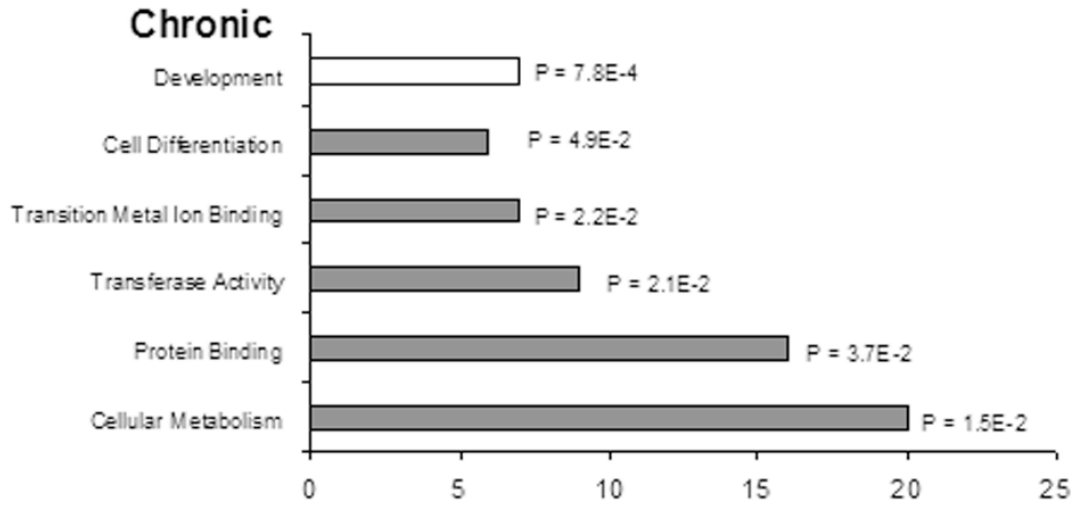

Common genes

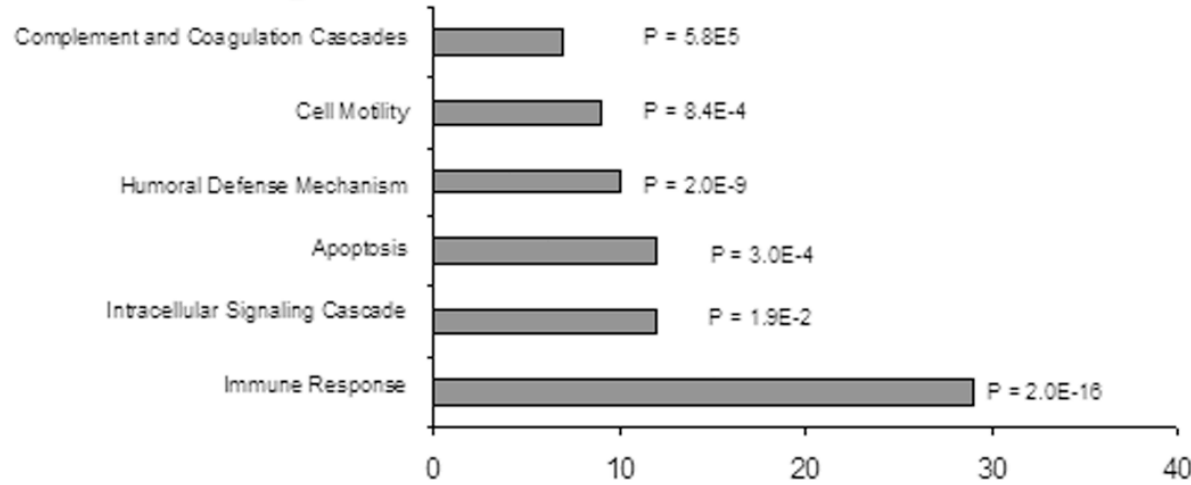

Figure 2 Functional classification of genes differentially expressed during epileptogenesis. Fisher Exact test was applied to identify functional categories over-represented among the genes regulated by SE in hippocampal cells, thereby ensuring statistical significance. D3 = three days after SE; D7 = seven days after SE; Chronic = immediately after the first spontaneous seizure; Common = genes found differentially expressed in all previous groups. 
Table 1 Genes commonly up-regulated throughout epileptogenesis, from the early events post-SE to the onset of recurrent spontaneous seizures.

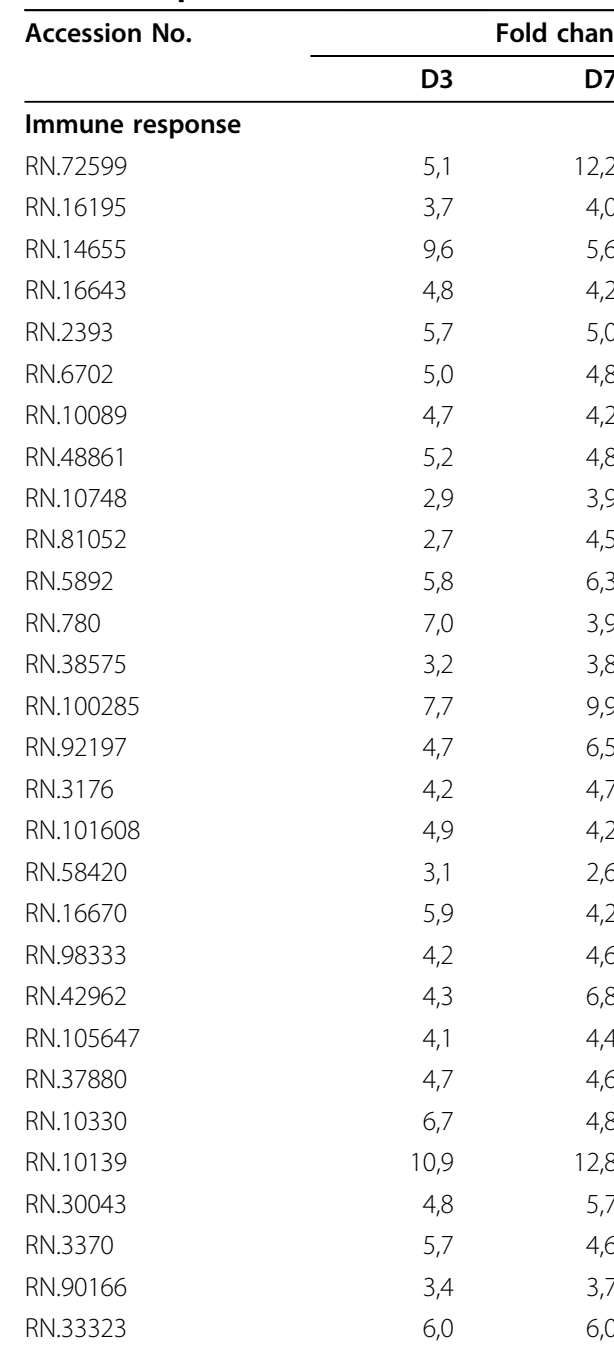

\section{Description}

D7 Chronic

Humoral Defense Mechanism

RN.81052

RN.72599

RN.100285

RN.2393

RN.10139

RN. 16670

RN.33323
7,4 colony stimulating factor 1 receptor

3,2 caspase 11

4,1 integrin alpha I

3,1 fc receptor, igg, high affinity i

3,6 complement component 1, q subcomponent, gamma polypeptide

3,1 complement component 1, q subcomponent, beta polypeptide

3,8 cyclin-dependent kinase inhibitor 1a

3,6 vav 1 oncogene

$5,5 \mathrm{~cd} 4$ antigen

4,5 complement component $4 a$

5,1 major histocompatibility complex, class ii, $\mathrm{dm}$ beta

4,1 alpha-2-macroglobulin

3,5 neutrophil cytosolic factor 1

8,3 serine (or cysteine) peptidase inhibitor, clade $\mathrm{g}$, member 1

5,9 linker for activation of $t$ cells family, member 2

3,8 lymphocyte antigen 86 (predicted)

4,5 lymphocyte specific 1

2,7 similar to ikappab-zeta (predicted)

4,5 basic leucine zipper transcription factor, atf-like (predicted)

4,0 complement component 2

6,2 integrin beta 2

3,3 complement component 1, q subcomponent, alpha polypeptide

5,6 small inducible cytokine a4

5,9 cd8 antigen, beta chain

10,1 chemokine (c-c motif) ligand 3

4,9 tumor necrosis factor (ligand) superfamily, member 4

4,3 interferon gamma inducible protein 30

3,2 protein tyrosine phosphatase, receptor type, c

4,8 fc receptor, igg, low affinity iib

3,3 complement component 1, q subcomponent, alpha polypeptide

4,5 complement component $4 a$

7,4 colony stimulating factor 1 receptor

8,3 serine (or cysteine) peptidase inhibitor, clade g, member 1

3,6 complement component 1, q subcomponent, gamma polypeptide

10,1 chemokine (c-c motif) ligand 3

4,5 basic leucine zipper transcription factor, atf-like (predicted)

3,1 complement component 1, q subcomponent, beta polypeptide

6,2 integrin beta 2

4,8 fc receptor, igg, low affinity iib

Complement and Coagulation Cascades

RN.81052 2,7

RN.780 
Table 1: Genes commonly up-regulated throughout epileptogenesis, from the early events post-SE to the onset of recurrent spontaneous seizures. (Continued)

\begin{tabular}{lr}
\hline RN.98333 & 4,2 \\
RN.21393 & 3,7 \\
Cell Motility & \\
RN.66513 & 5,8 \\
RN.6282 & 5,0 \\
RN.2090 & 3,7 \\
RN.14655 & 9, \\
RN.95169 & 3,2 \\
RN.101608 & 4, \\
RN.10139 & 10,9 \\
RN.49170 & 4,7 \\
RN.42962 & 4,3
\end{tabular}

$4,2 \quad 4,6$

$3,7 \quad 6,5$

4,0 complement component 2

5,7 coagulation factor $x$

Apoptosis

RN.66513

RN.6282

RN.16195

RN.16643

RN.101608

RN.3176

RN.7110

RN.18985

RN.42962

RN.10089

RN.90166

RN.10250

$\begin{array}{rr}5,8 & 7,2 \\ 5,0 & 5,0 \\ 3,7 & 3,4 \\ 9,6 & 5,6 \\ 3,2 & 3,7 \\ 4,9 & 4,2 \\ 10,9 & 12,8 \\ 4,7 & 4,4 \\ 4,3 & 6,8\end{array}$

6,8
5,8 arachidonate 12-lipoxygenase (predicted)

4,8 insulin-like growth factor 1

2,7 actin related protein $2 / 3$ complex, subunit $1 \mathrm{~b}$

4,1 integrin alpha I

3,0 abi gene family, member 3

4,5 lymphocyte specific 1

10,1 chemokine (c-c motif) ligand 3

3,4 suppression of tumorigenicity 14

6,2 integrin beta 2

Intracellular Signaling Cascade

$\begin{array}{lrrl}\text { RN.6282 } & 5,0 & 5,0 & 4,8 \text { insulin-like growth factor 1 } \\ \text { RN.68084 } & 6,3 & 4,3 & 7,7 \text { b-cell leukemia/lymphoma 3 (predicted) } \\ \text { RN.780 } & 7,0 & 3,9 & 4,1 \text { alpha-2-macroglobulin } \\ \text { RN.35286 } & 3,4 & 4,0 & 2,9 \text { similar to ptpl1-associated rhogap 1 (predicted) } \\ \text { RN.138976 } & 3,3 & 3,6 & 2,9 \text { sh3-domain binding protein 2 } \\ \text { RN.19450 } & 19,4 & 25,9 & 18,5 \text { adenylate cyclase 7 } \\ \text { RN.38575 } & 3,2 & 3,8 & 3,5 \text { neutrophil cytosolic factor 1 } \\ \text { RN.7110 } & 6,0 & 4,9 & 4,2 \text { receptor-interacting serine-threonine kinase } 3 \\ \text { RN.18985 } & 4,0 & 5,0 & 3,3 \text { protein tyrosine phosphatase, non-receptor type 6 } \\ \text { RN.11534 } & 3,6 & 3,8 & 3,2 \text { tyro protein tyrosine kinase binding protein } \\ \text { RN.10748 } & 2,9 & 3,9 & 5,5 \text { cd4 antigen } \\ \text { RN.48861 } & 5,2 & 4,8 & 3,6 \text { vav } 1 \text { oncogene } \\ \text { RN.40136 } & 3,5 & 4,3 & 3,2 \text { transforming growth factor, beta 1 }\end{array}$

*Only those genes and their corresponding functional classes found specifically enriched and significantly associated with epileptogenesis are shown $(P$-values $\leq$ 0.001 , according to the Fisher Exact Test for functional enrichment analysis). Expression data is given as fold change from control, at the three time points analyzed after SE (D3 = three days after SE; D7 = seven days after SE; Chronic = immediately after the first spontaneous seizure).

One distinct aspect of the present study is that the experiments were designed to cover all possible changes in the transcriptome of hippocampal cells, using a microarray platform containing more than 34,000 oligonucleotide probes representing transcripts from all annotated rat genes to date. This whole-genome profiling was conducted at three close time-points during the course of epileptogenesis, according to the pilocarpine model of epilepsy: three and seven days post-SE, corresponding to early and mid term of the latent phase, and immediately after the first spontaneous seizure which corresponds to the onset of the chronic phase. The major aim was to uncover genes 
Table 2 Regulatory signal transduction pathways and corresponding gene members found differentially expressed during epileptogenesis.

\begin{tabular}{|c|c|c|c|c|c|c|c|c|}
\hline \multirow{2}{*}{$\begin{array}{l}\text { Signaling } \\
\text { Pathway }\end{array}$} & \multicolumn{2}{|c|}{ D3 vs. CTRL } & \multicolumn{2}{|c|}{ D7 vs. CTRL } & \multicolumn{2}{|c|}{ CHRONIC vs. CTRL } & \multicolumn{2}{|c|}{ D3, D7 and CHRONIC vs. CTRL } \\
\hline & Up-regulated & $\begin{array}{l}\text { Down- } \\
\text { regulated }\end{array}$ & $\begin{array}{c}\text { Up- } \\
\text { regulated }\end{array}$ & $\begin{array}{l}\text { Down- } \\
\text { regulated }\end{array}$ & Up-regulated & $\begin{array}{l}\text { Down- } \\
\text { regulated }\end{array}$ & Up-regulated & $\begin{array}{c}\text { Down- } \\
\text { regulated }\end{array}$ \\
\hline MAPK & Tgfbri, Acvr1c & Prkcc & Tgfb 1 & - & $\begin{array}{c}\text { P38 Mapk, Fgf7, } \\
\text { Rasa2 }\end{array}$ & Map2k1 & $\begin{array}{c}\text { Cacnalg, Casp4, } \\
\text { Gadd45a }\end{array}$ & - \\
\hline Wnt & Plcb2 & Prkcc & - & - & - & - & - & - \\
\hline Notch & - & Hes5 & - & - & - & - & - & - \\
\hline TGF-beta & $\begin{array}{c}\text { Tgfbr1, Tgfb1, } \\
\text { Acvrlc }\end{array}$ & - & Tgfb 1 & - & Tgfb1 & - & Tgfb 1 & - \\
\hline Jak-STAT & Stat3, Jak3 & - & $\begin{array}{l}\text { Pik3r1, } \\
\text { Ifngri }\end{array}$ & - & Pik3r3 & - & Csf2rb1 & - \\
\hline Calcium & Plcb2 & Prkcc, Cckbr & - & - & - & - & Cacnalg & - \\
\hline $\begin{array}{l}\text { Phosphatidyl } \\
\text { Inositol }\end{array}$ & Plcb2 & Prkcc & Pik3r1 & - & Pik3r3 & - & $P i k 3 c 2 b$ & - \\
\hline mTOR & Igf1 & & $\operatorname{lgf1}$ & & lgf1 & & Igfi & \\
\hline
\end{tabular}

${ }^{*} \mathrm{D} 3$ = three days post-SE; D7 = seven days post-SE; Chronic = immediately after the first spontaneous seizure; CTRL = saline-treated, time-matched control.

that might be involved in development of epilepsy and not solely correlated with $S E$ or seizures. However, given that this strategy was applied to the whole hippocampus, information regarding particular cell types and subregions within the hippocampus in which abnormal gene expression occurs is not available and should be further investigated.

Nonetheless, since pilocarpine-treated animals generally return to normal behavior within three days post$S E$, a molecular analysis at this time point should capture the early events leading to epilepsy with minimal contamination by genes regulated in response to the chemical treatment per se or as a consequence of tissue damage. However, many of the genes found differentially expressed three days post- $S E$ were related to stress response including participation in defense mechanisms and wound healing. This result is in agreement with a previous study by Becker et al., 2003 [12] reporting, three days post-SE, a high proportion of up-regulated genes in the dentate gyrus and CA1 regions of the hippocampus being associated with cellular stress and injury. However, under the same experimental condition, we also found a large group of genes functioning in cell proliferation and migration, supporting that neurogenesis is triggered early in latent phase.

In agreement with this assumption, quantitative real-time PCR analysis of cell cycle genes confirmed hyper-expression of $C D K 1$, a gene regulating the $\mathrm{G} 1$ to $\mathrm{S}$ and $\mathrm{G} 2$ to $\mathrm{M}$ transition of the cell cycle, and Nestin, a marker of neural stem cells and neural progenitor cells. However, expression of the cell cycle inhibitor p18(INK4c) was paradoxically enhanced after $S E$ and coincide with the peak of $C D K 1$ and Nestin expression at day three post-SE. No significant differences in the expression of these genes were observed seven days post- $S E$ or after the first spontaneous seizure.
Recent studies have reported that members of the cyclin dependent kinase family are up-regulated during epileptogenesis [30]. However, the hyper-expression of the cell cycle inhibitor $p 18(I N K 4 c)$ found after $S E$ had not been previously reported. This finding suggests that the proliferative stage of neurogenesis in the hippocampus of adult rats may be inhibited by such activation of $p 18(I N K 4 c)$.

Moreover, when examining gene expression profiles in animals that had experienced only one spontaneous seizure after $S E$, a time by when all essential changes for the installation of epilepsy are expected to be manifested in the central nervous system, there was a primarily upregulation of genes functioning in protein expression and post-translational processing, including many transcription factors, kinases and other transferases, along with genes regulating cell differentiation such as FOXD3 and RUNX1. These two genes are of particular interest since they encode transcription factors involved in maintenance of embryonic stem cell pluripotency and proliferation of neural progenitors, respectively [31,32]. Since commitment of stem cells to the neuronal lineage is associated with repression of FOXD3 expression [33], it is reasonable to assume that its hyper-expression could be implicated in inhibition of neuroprogenitor differentiation. This observation is in line with a marked repression of genes regulating cell fate, development, and morphogenesis such as $L D B 2, B M P 3$, and MAP2K1 detected in pilocarpine-treated animals at the beginning of the chronic phase.

Altogether, these findings suggest that neurogenesis may be impaired by different mechanisms throughout the period corresponding to the latent to chronic phase transition of the pilocarpine model. Indeed, anomalous neurogenesis has been implicated in the development of epilepsy $[34,35]$. Prolonged seizures are known to 


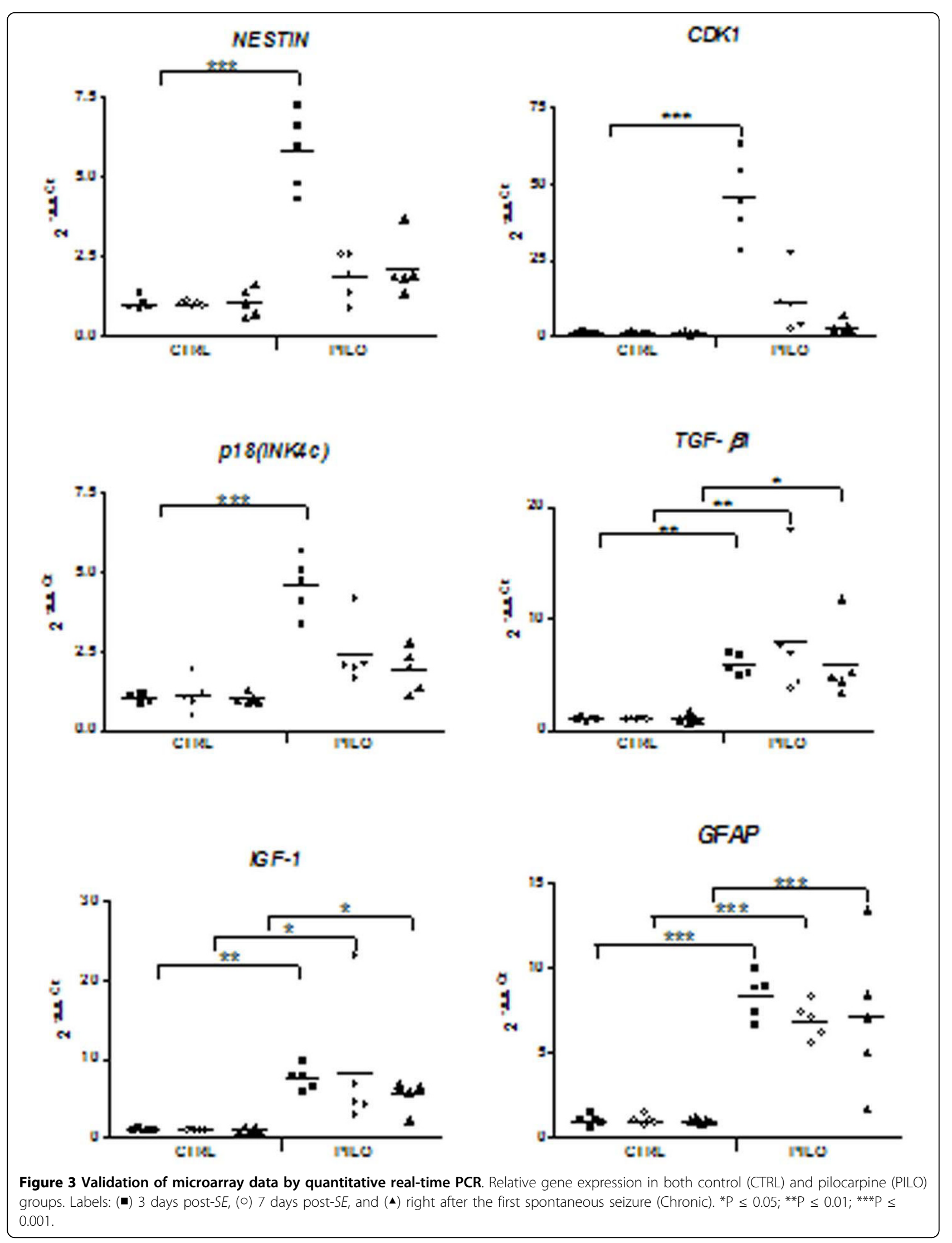


stimulate neurogenesis in the dentate gyrus, although new born neurons display abnormal apical dendritic morphology, and the ensuing plasticity of the hippocampal network can lead to aberrant neuronal connections associated with epileptogenesis [36,37]. Furthermore, fate decision of proliferating neuronal progenitors in the hippocampus has been reported to be impaired after intra-hippocampal injection of kainic acid, favoring astrogliosis [38]. Prolonged seizures have also been reported to induce aberrant migration of newborn neurons to the hilus and inner molecular layer of the dentate gyrus, contributing to the formation of a hyperexcitable circuitry $[39,35]$.

Another intriguing result that emerged from the comparative analysis of genes differentially expressed at each of the three time points post-SE was the identification of a group of 128 genes continually up-regulated throughout the course of epileptogenesis. This finding was somewhat unexpected since cellular activity in response to its microenvironment stimuli is dynamically regulated through transient and specific changes in gene expression. One possible interpretation is that the $S E$ may cause stable alterations in the microenvironment, exposing the remaining cells to nonstandard cues. Alternatively, the nature of cell population within the hippocampus may be shifted after $S E$, accommodating a greater proportion of activated microglial cells and other cells of abnormal phenotype expressing a different repertoire of genes.

Consistent with the literature, a functional classification of these 128 up-regulated genes indicated that most of them are involved in signaling cascades, extracellular matrix remodeling and cell motility, apoptosis, and immune response, which are processes known to be associated with epileptic seizures. In particular, the high proportion of immune response genes and the activation of genes from the p38 MAPK signaling pathway, some of which confirmed by real-time PCR, are in agreement with a chronic activation of microglial cells [40]. Furthermore, up-regulation of proinflammatory genes in both cortex and hippocampus of patients with TLE have been recently reported [41].

Based on experimental and clinical evidences, inflammation and neurogenesis seem to be common factors contributing to the development of epilepsy. Since microglia activation suppresses hippocampal neurogenesis in adult brain [42], modulation of genes and pathways connecting both processes should have an impact on epileptogenesis. Whether some of the genes hereby found regulated during epileptogenesis should fall into this category of relevance remains to be elucidated. Interestingly, the steady up-regulation of the inflammatory peptide TGF-beta1 detected throughout epileptogenesis might be one of such factors contributing to an anomalous neurogenesis. This hypothesis is reinforced by a recent report by Cacheaux et al., 2009 [43], describing involvement of the TGF-beta pathway in the development of epilepsy caused by brain injury.

\section{Conclusions}

In summary, our whole-genome screening indicate remarkable changes in the rat transcriptome along the latent to chronic phase transition of the pilocarpine model of epilepsy. Over a thousand genes had their expression altered after $S E$, most of which displaying an up-regulation, and their functional classification provide a molecular portrait of the epileptogenic process. There was a consistent regulation of genes functioning in neurogenesis, apoptosis, immune response, and intracellular signal transduction, some of which with parallel expression patterns in patients with epilepsy, strengthening the link between these processes and development of TLE. Most differentially expressed genes identified are novel and could now be further tested to provide experimental and clinical evidences of functional relevance to epileptogenesis. In particular, genes mediating inflammation and neurogenesis such as those from the TGF-beta signaling pathway are of particular interest and shall be pursued as targets for molecular therapy.

\section{Acknowledgements}

This work was supported by grants from Fundação de Amparo 'a Pesquisa do Estado de São Paulo (FAPESP No. 02/01826-5 and CInAPCe). L.J., F.M.B., and A.P.P. were recipients of PhD fellowships from CAPES and CNPq.

\section{Author details}

'Disciplina de Neurologia Experimental, Departamento de Neurologia e Neurocirurgia, Universidade Federal de São Paulo. ${ }^{2}$ Departamento de Biociências, Universidade Federal de São Paulo.

\section{Authors' contributions}

OKO conceived the study, conducted experiments, discussed results and wrote the manuscript. EAC conceived the study, discussed results and revised the manuscript. AVS \& FAS discussed results and revised the manuscript. L.J., F.M.B., and A.P.P conducted experiments, discussed results and help writing the manuscript. All authors have read and approved the final manuscript.

Received: 12 November 2009 Accepted: 8 April 2010 Published: 8 April 2010

\section{References}

1. Sander JW: The epidemiology of epilepsy revisited. Curr Opin Neurol 2003, 16:165-10.

2. Kwan P, Sander JW: The natural history of epilepsy: an epidemiological view. J Neurol Neurosurg Psychiatry 2004, 75:376-381.

3. Engel J Jr: Clinical neurophysiology, neuroimaging, and the surgical treatment of epilepsy. Curr Opin Neurol Neurosurg 1993, 6(Suppl 2):240-249.

4. Dalby NO, Mody I: The process of epileptogenesis: a pathophysiological approach. Curr Opin Neurol 2001, 14:187-192.

5. Arion D, Sabatini M, Unger T, Pastor J, Alonso-Nanclares L, BallesterosYanez I, Garcia Sola R, Munoz A, Mirnics K, DeFelipe J: Correlation of transcriptome profile with electrical activity in temporal lobe epilepsy. Neurobiol Dis 2006, 22:374-387.

6. Jamali S, Bartolomei F, Robaglia-Schlupp A, Massacrier A, Peragut JC, Regis J, Dufour H, Ravid R, Roll P, Pereira S, Royer B, Roeckel-Trevisiol N, 
Fontaine M, Guye M, Boucraut J, Chauvel P, Cau P, Szepetowski P: Largescale expression study of human mesial temporal lobe epilepsy: evidence for dysregulation of the neurotransmission and complement systems in the entorhinal cortex. Brain 2006, 129:625-641.

7. Berkovic SF, Dibbens LM, Oshlack A, Silver JD, Katerelos M, Vears DF, Lüllmann-Rauch R, Blanz J, Zhang KW, Stankovich J, Kalnins RM, Dowling JP, Andermann E, Andermann F, Faldini E, D'Hooge R, Vadlamudi L, Macdonell RA, Hodgson BL, Bayly MA, Savige J, Mulley JC, Smyth GK, Power DA, Saftig P, Bahlo M: Array-based gene discovery with three unrelated subjects shows SCARB2/LIMP-2 deficiency causes myoclonus epilepsy and glomerulosclerosis. Am J Hum Genet 2008, 82:673-684.

8. Helbig I, Matigian NA, Vadlamudi L, Lawrence KM, Bayly MA, Bain SM, Diyagama D, Scheffer IE, Mulley JC, Holloway AJ, Dibbens LM, Berkovic SF, Hayward NK: Gene expression analysis in absence epilepsy using a monozygotic twin design. Epilepsia 2008, 49:1546-1554.

9. Xi ZQ, Xiao F, Yuan J, Wang XF, Wang L, Quan FY, Liu GW: Gene expression analysis on anterior temporal neocortex of patients with intractable epilepsy. Synapse 2009, 63:1017-1028.

10. Scharfman HE, Gray WP: Relevance of seizure-induced neurogenesis in animal models of epilepsy to the etiology of temporal lobe epilepsy. Epilepsia 2007, 48:33-41.

11. Hunsberger JG, Bennett AH, Selvanayagam E, Duman RS, Newton SS: Gene profiling the response to kainic acid induced seizures. Brain Res Mol 2005, 141:95-112.

12. Becker AJ, Chen J, Zien A, Sochivko D, Normann S, Schramm J, Elger CE, Wiestler OD, Blümcke I: Correlated stage- and subfield-associated hippocampal gene expression patterns in experimental and human temporal lobe epilepsy. Eur J Neurosci 2003, 18:2792-802.

13. Elliott RC, Miles MF, Lowenstein DH: Overlapping microarray profiles of dentate gyrus gene expression during development- and epilepsyassociated neurogenesis and axon outgrowth. J Neurosci 2003, 23:2218-2227.

14. Lukasiuk $K$, Kontula L, Pitkanen A: cDNA profiling of epileptogenesis in the rat brain. Eur J Neurosci 2003, 17:271-279.

15. Gorter JA, van Vliet EA, Aronica E, Breit T, Rauwerda H, Lopes da Silva FH, Wadman WJ: Potential new antiepileptogenic targets indicated by microarray analysis in a rat model for temporal lobe epilepsy. J Neurosci 2006, 26:11083-11110.

16. Turski L, Ikonomidou C, Turski WA, Bortolotto ZA, Cavalheiro EA: Cholinergic mechanisms and epileptogenesis. The seizures induced by pilocarpine: a novel experimental model of intractable epilepsy. Synapse 1989, 3:154-171.

17. Cavalheiro EA, Leite JP, Bortolotto ZA, Turski WA, Ikonomidou C, Turski L: Long-term effects of pilocarpine in rats: structural damage of the brain triggers kindling and spontaneous recurrent seizures. Epilepsia 1991, 32:778-782.

18. Curia G, Longo D, Biagini G, Jones RS, Avoli M: The pilocarpine model of temporal lobe epilepsy. J Neurosci Methods 2008, 172:143-157.

19. Turski WA, Cavalheiro EA, Schwarz M, Czuczwar SJ, Kleinrok Z, Turski L: Limbic seizures produced by pilocarpine in rats: behavioural, electroencephalographic and neuropathological study. Behav Brain Res 1983, 9:315-335.

20. Leite JP, Bortolotto ZA, Cavalheiro EA: Spontaneous recurrent seizures in rats: an experimental model of partial epilepsy. Neurosci Biobehav Rev 1990, 14:511-517.

21. Eisen $M B$, Spellman PT, Brown PO, Botstein D: Cluster analysis and display of genome-wide expression patterns. Proc Natl Acad Sci 1998, 95:14863-14868

22. Dennis G Jr, Sherman BT, Hosack DA, Yang J, Gao W, Lane HC, Lempicki RA DAVID: Database for Annotation, Visualization, and Integrated Discovery. Genome Biol 2003, 4(5):P3.

23. Kanehisa M, Goto S: KEGG: kyoto encyclopedia of genes and genomes. Nucleic Acids Res 2000, 28:27-30.

24. Ashburner M, Ball CA, Blake JA, Botstein D, Butler H, Cherry JM, Davis AP, Dolinski K, Dwight SS, Eppig JT, Harris MA, Hill DP, Issel-Tarver L, Kasarskis A, Lewis S, Matese JC, Richardson JE, Ringwald M, Rubin GM, Sherlock G: Gene ontology: tool for the unification of biology. The Gene Ontology Consortium. Nat Genet 2000, 25:25-29.

25. Wu X, Yoo S, Wrathall JR: Real-time quantitative PCR analysis of temporalspatial alterations in gene expression after spinal cord contusion. IJ Neurochemistry 2005, 93:943-952.
26. Turner KJ, McIntyre BS, Phillips SL, Barlow NJ, Bowman CJ, Foster PMD: Altered gene expression during rat wolffian duct development in response to in utero exposure to the antiandrogen linuron. Toxicol Sci 2003, 74:114-128.

27. Wang JM, Johnston PB, Ball BG, Brinton RD: The neurosteroid allopregnanolone promotes proliferation of rodent and human neural progenitor cells and regulates cell-cycle gene and protein expression. J Neurosci 2005, 19:4706-4718.

28. Ji JF, Dheen ST, Kumar SD, He BP, Tay SSW: Expressions of cytokines and chemokines in the dorsal motor nucleus of the vagus nerve after right vagotomy. Mol Brain Res 2005, 142:47-57.

29. Mandhan P, Beasley S, Hale T, Ellmers L, Roake J, Sullivan M: Sonic hedgehog expression in the development of hindgut in ETU-exposed fetal rats. Pediatr Surg Int 2006, 22:31-36.

30. Murashima YL, Suzuki J, Yoshii M: Cell cycle reentry and cell proliferation as candidates for the seizure predispositions in the hippocampus of EL mouse brain. Epilepsia 2007, 48(Suppl 5):119-125.

31. Theriault FM, Nuthall HN, Dong Z, Lo R, Barnabe-Heider F, Miller FD, Stifani S: Role for Runx 1 in the proliferation and neuronal differentiation of selected progenitor cells in the mammalian nervous system. J Neurosci 2005, 25:2050-2061.

32. Pan $G, L i$ J, Zhou $Y$, Zheng $H$, Pei D: A negative feedback loop of transcription factors that controls stem cell pluripotency and selfrenewal. FASEB J 2006, 20:1730-1732.

33. Perry P, Sauer S, Billon N, Richardson WD, Spivakov M, Warnes G, Livesey FJ, Merkenschlager M, Fisher AG, Azuara V: A dynamic switch in the replication timing of key regulator genes in embryonic stem cells upon neural induction. Cell Cycle 2004, 3:1645-1650.

34. Parent JM, Yu TW, Leibowitz RT, Geschwind DH, Sloviter RS, Lowenstein DH: Dentate granule cell neurogenesis is increased by seizures and contributes to aberrant network reorganization in the adult rat hippocampus. J Neurosci 1997, 17:3727-3738.

35. Parent JM, Elliott RC, Pleasure SJ, Barbaro NM, Lowenstein DH: Aberrant seizure-induced neurogenesis in experimental temporal lobe epilepsy. Ann Neurol 2006, 59:81-91.

36. Arisi GM, Garcia-Cairasco N: Doublecortin-positive newly born granule cells of hippocampus have abnormal apical dendritic morphology in the pilocarpine model of temporal lobe epilepsy. Brain Res 2007, 1165:126-134

37. Parent JM: Adult neurogenesis in the intact and epileptic dentate gyrus. Prog Brain Res 2007, 163:529-540

38. Ledergerber D, Fritschy JM, Kralic JE: Impairment of dentate gyrus neuronal progenitor cell differentiation in a mouse model of temporal lobe epilepsy. Exp Neurol 2006, 199:130-142.

39. Scharfman HE, Goodman JH, Sollas AL: Granule-like neurons at the hilar/ CA3 border after status epilepticus and their synchrony with area CA3 pyramidal cells: functional implications of seizure-induced neurogenesis. J Neurosci 2000, 20:6144-6158.

40. Choi YS, Cho HY, Hoyt KR, Naegele JR, Obrietan K: IGF-1 receptormediated ERK/MAPK signaling couples status epilepticus to progenitor cell proliferation in the subgranular layer of the dentate gyrus. Glia 2008 , 56:791-800.

41. Argañaraz GA, Konno AC, Perosa SR, Santiago JF, Boim MA, Vidotti DB, Varella PP, Costa LG, Canzian M, Porcionatto MA, Yacubian EM, Sakamoto AC, Carrete H Jr, Centeno RS, Amado D, Cavalheiro EA, Junior JA, Mazzacoratti MG: The renin-angiotensin system is upregulated in the cortex and hippocampus of patients with temporal lobe epilepsy related to mesial temporal sclerosis. Epilepsia 2008, 49:1348-1357.

42. Ekdahl $\mathrm{CT}$, Claasen JH, Bonde S, Kokaia Z, Lindvall O: Inflammation is detrimental for neurogenesis in adult brain. Proc Natl Acad Sci 2003, 100:13632-13637.

43. Cacheaux LP, Ivens S, David Y, Lakhter AJ, Bar-Klein G, Shapira M, Heinemann U, Friedman A, Kaufer D: Transcriptome profiling reveals TGFbeta signaling involvement in epileptogenesis. J Neurosci 2009, 29:8927-8935.

doi:10.1186/1471-2164-11-230

Cite this article as: Okamoto et al:: Whole transcriptome analysis of the hippocampus: toward a molecular portrait of epileptogenesis. BMC Genomics 2010 11:230. 